\title{
Gas Sensors Based on Polymer Field-Effect Transistors
}

\author{
Aifeng Lv ${ }^{1}$, Yong Pan ${ }^{1}$ and Lifeng Chi ${ }^{1,2, *}$ \\ 1 Physikalisches Institut and Center for Nanotechnology (CeNTech), Universität Münster, \\ Wilhelm-Klemm-Str. 10, Münster 48149, Germany; lva@uni-muenster.de (A.L.); pany@uni-muenster.de (Y.P.) \\ 2 Jiangsu Key Laboratory for Carbon-Based Functional Materials \& Devices, Functional Nano and Soft \\ Materials Laboratory (FUNSOM), Soochow University, Renai Rd. 199, Suzhou 215123, China \\ * Correspondence: chilf@suda.edu.cn or chi@uni-muenster.de \\ Academic Editors: Eduard Llobet and Stella Vallejos \\ Received: 29 November 2016; Accepted: 4 January 2017; Published: 22 January 2017
}

\begin{abstract}
This review focuses on polymer field-effect transistor (PFET) based gas sensor with polymer as the sensing layer, which interacts with gas analyte and thus induces the change of source-drain current $\left(\Delta I_{\mathrm{SD}}\right)$. Dependent on the sensing layer which can be semiconducting polymer, dielectric layer or conducting polymer gate, the PFET sensors can be subdivided into three types. For each type of sensor, we present the molecular structure of sensing polymer, the gas analyte and the sensing performance. Most importantly, we summarize various analyte-polymer interactions, which help to understand the sensing mechanism in the PFET sensors and can provide possible approaches for the sensor fabrication in the future.
\end{abstract}

Keywords: OFETs; sensor; gas analyte; polymer; sensing mechanism

\section{Introduction}

Organic field-effect transistor (OFET) based gas sensors have attracted great interest due to the high selectivity, repeatable response and low-cost production [1-6]. The organic materials, which interact with gas analytes, can fine-tune their chemical and physical properties via precise organic synthesis. Additionally, covalent integration of recognition groups onto the sensing molecules can provide specific interaction with designated analytes, thus significantly increasing the selectivity and response. The thin films of organic materials can be deposited by printing technology at low temperatures on flexible substrate. As a result, miniaturization and high integration of these sensors at low cost are achievable. Moreover, the device configuration of OFETs and the instrument for the response measurement are relatively simple. These advantages endow the OFET sensors with great potential application in electronic nose, which can reproduce the human sensing with sensor arrays and pattern recognition systems. Such electronic nose is similar to human olfaction, which has applications of identification, comparison, quantification, data storage and retrieval.

There are mainly two types of organic electrical sensors: chemiresistor and OFET. Chemiresistor sensors exhibit change of resistance toward gas analytes that have not yet reached satisfactory performance. OFET sensors become more competitive due to the ability of delivering multi-parameter response, for example, charge carrier mobility $(\mu)$, threshold voltage $\left(V_{\mathrm{T}}\right)$, on / off-current $\left(I_{\mathrm{ON}} / I_{\mathrm{OFF}}\right)$ of the devices, and the bulk conductivity $(\sigma)$ of the organic semiconducting film $[7,8]$. Such devices can display fingerprint response for the detection of a wide range of analytes at low concentration. In an OFET sensor, charge carrier mobility is a very important factor as it relates with the signal transfer speed [9]. Therefore, OFET sensors based on the small molecular semiconductors have attracted great scientific interest due to the crystalline packing in the thin film and the resulting high charge carrier mobility. However, small molecular semiconductors are normally fabricated in a high-vacuum 
set-up by which the fabrication process is expensive and time-consuming. On the opposite side, semiconducting polymers have cost effectiveness, easy processing and compatibility with plastic substrate, and therefore have great advantageous applications in the electronic nose. However, OFET sensors have not been conducted on many existing polymer semiconductors (Scheme 1, Table 1), and previous literature has mainly focused on the research of charge carrier transport [10].

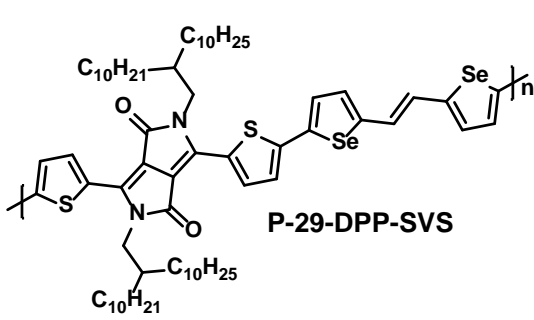

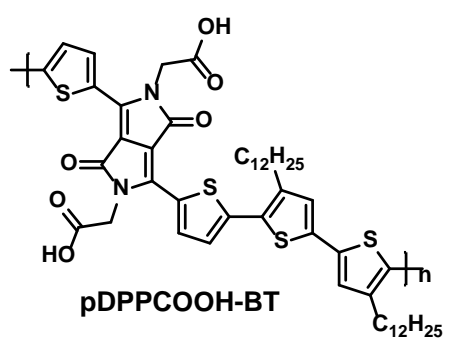<smiles>[R]c1csc(I)c1</smiles>

$\mathrm{R}=$ hexyl, P3HT

$\mathrm{R}=$ butyl, poly-3-butylthiophene $\mathrm{R}=$ octyl, poly-3-octylthiophene

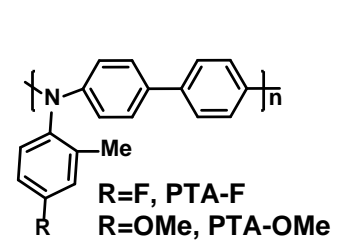<smiles>Cc1ccccc1-c1ccc(CN)cc1</smiles><smiles>[2H]c1cc(C)sc1-c1ccc(-c2sc(C)cc2P)s1</smiles>

P3HT-benzylamine

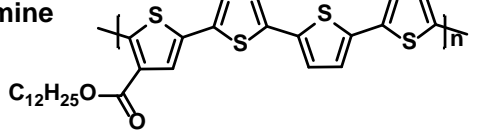

$\mathrm{R}=\mathrm{C}_{12} \mathrm{H}_{25}$, poly-DDT $\mathrm{R}=\mathrm{OC}_{5} \mathrm{H}_{11}$, poly-DPOT

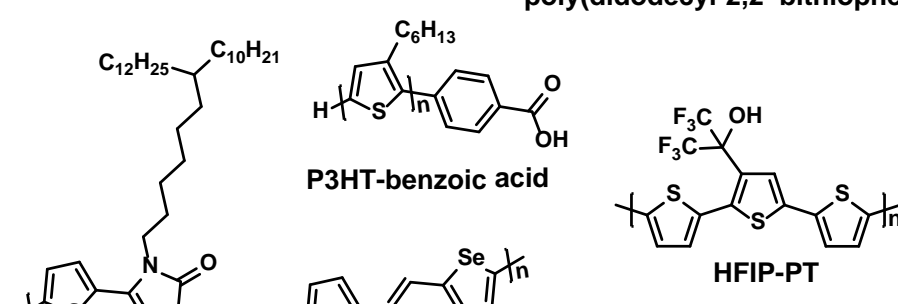

poly(didodecyl-2,2'-bithiophene-4,4'-dicarboxy-late-co-2,2'-bithiophene)<smiles>CCCc1cc(C)sc1-c1ccc(-c2ccc(-c3ccc(C)s3)s2)s1</smiles>

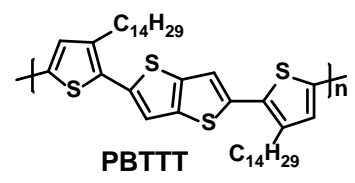<smiles>Cc1ccsc1-c1ccc(N)cc1</smiles>

P3HT-aniline

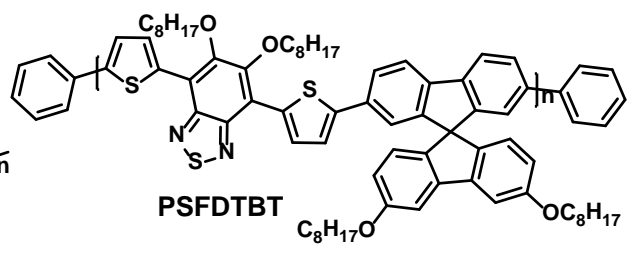<smiles>CN(O)c1ccc(Nc2ccc(Nc3ccccc3)cc2)cc1</smiles>

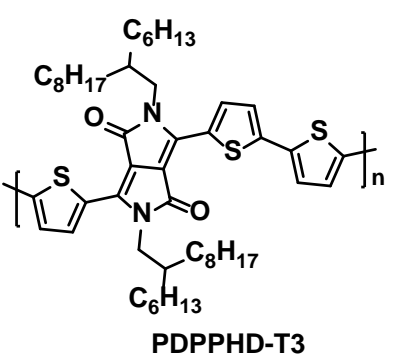

Scheme 1. Reported molecular structures of semiconducting polymer used in the OFET sensors. 
Table 1. Summary of the sensing polymer semiconductors and the key parameters of PFET sensors.

\begin{tabular}{|c|c|c|c|c|c|c|c|}
\hline Materials & Analytes & /ppm & Device & $-V_{\mathrm{DS}} / \mathrm{V}$ & $-V_{\mathrm{GS}} / \mathrm{V}$ & Response Time & Reference \\
\hline \multirow{8}{*}{ P3HT } & $\mathrm{NH}_{3}$ & $100 \%$ & BGBC & 4 & 4 & $10 \mathrm{~min}$ & [11] \\
\hline & $\mathrm{NH}_{3}$ & $0.03-1$ & Vertical & 1 & 1 & - & [12] \\
\hline & $\mathrm{NH}_{3}$ & $0.1-25$ & BGBC & 60 & 30 & $5-25 \mathrm{~s}$ & [13] \\
\hline & $\mathrm{NH}_{3}$ & 16-198 & BGBC & 1 & 1 & 52 s (99 ppm) & [14] \\
\hline & $\mathrm{NH}_{3}$ & 100 & BGBC & $100 / 10$ & 85 & $600 \mathrm{~s}$ & [15] \\
\hline & $\mathrm{NO}_{2}$ & $0.038-25$ & BGBC & 50 & 50 & $5 \mathrm{~min}$ & [16] \\
\hline & ethanol acetone & $500-7000$ & BGBC & 60 & 60 & $8-15 \mathrm{~min}$ & [17] \\
\hline & ethanol methanol & $\mathrm{SVP}^{3}$ & TGTC & 2 & 0.8 & - & [18] \\
\hline P-29-DPP-SVS & $\mathrm{NH}_{3}$ & 29-1000 & BGTC & 5 & 5 & $5 \mathrm{~min}$ & [20] \\
\hline \multirow[b]{2}{*}{ pDPPCOOH-BT } & $\mathrm{NH}_{3}$ & $0.01-1000$ & BGBC & 60 & 80 & $50 \mathrm{~s}$ & [21] \\
\hline & $\begin{array}{l}\text { 1,4-diaminobutane, } \mathrm{Et} 3 \mathrm{~N}, \\
\text { piperidine }\end{array}$ & 10 ppm & BGBC & 60 & 80 & $50 \mathrm{~s}$ & [21] \\
\hline $\mathrm{P} 3 \mathrm{HT} / \mathrm{PS}$ & $\mathrm{NH}_{3}$ & $5-50$ & BGTC & 40 & \multirow{3}{*}{$\begin{array}{c}40 \\
\text { corona } \\
\text { charge } \\
10\end{array}$} & 5-10 min & [22] \\
\hline PQT-12 & $\mathrm{NH}_{3}$ & $0.1-15$ & BGBC & 90 & & $\geq 5 \mathrm{~min}$ & [23] \\
\hline polyaniline & $\mathrm{NH}_{3}$ & $1-20$ & BGBC & 8 & & $10 \mathrm{~s}$ & [24] \\
\hline PBTTT & DMNB & 6.5 & BGTC & 100 & 53 & $10 \mathrm{~min}-20 \mathrm{~h}$ & [26] \\
\hline Array sensor of Poly-3-butylthiophene & octylamine butylamine & 8.9 & BGBC & 20 & 20 & $900 \mathrm{~s}$ & [27] \\
\hline Poly-3-octylthiophene & hexylamine triethylamine & 30 & BGBC & 20 & 20 & 900 & [27] \\
\hline $\begin{array}{c}\text { PTA-F } \\
\text { PTA-OMe }\end{array}$ & $\mathrm{NO}_{2}$ & $0.01-50$ & BGTC & 3 & 3 & $20 \mathrm{~s}$ & {$[28]$} \\
\hline DPP-SVS/GO $^{1}$ & ethanol & $\mathrm{SVP}^{3}$ & BGTC & 30 & 30 & $20 \mathrm{~s}$ & [29] \\
\hline $\mathrm{F} 8 \mathrm{~T} 2 / \mathrm{GO}$ & ethanol acetone & $\mathrm{SVP}^{3}$ & BGTC & 80 & 80 & $10 \mathrm{~min}$ & [30] \\
\hline $\begin{array}{c}\text { Poly-DPOT } \\
\text { Poly-DDT }\end{array}$ & Ethanol 1-hexanol & 700 & BGBC & 100 & 40 & $2 \mathrm{~min}$ & {$[31,32]$} \\
\hline PSFDTBT & $\mathrm{H}_{2} \mathrm{~S}$ & $0.001-1$ & BGTC & 30 & 30 & $5-15 \mathrm{~s}$ & [33] \\
\hline
\end{tabular}


Table 1. Cont.

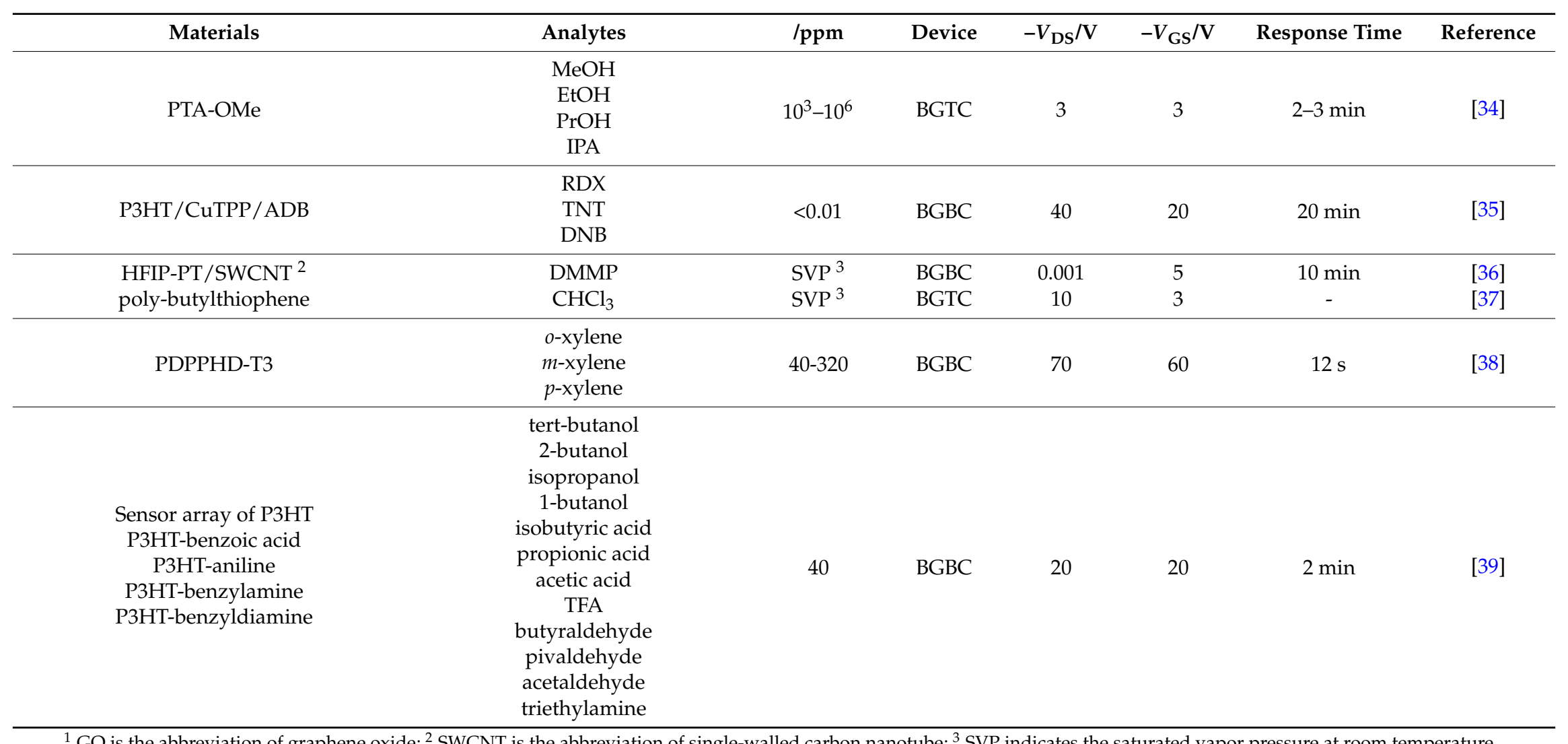

${ }^{1} \mathrm{GO}$ is the abbreviation of graphene oxide; ${ }^{2} \mathrm{SWCNT}$ is the abbreviation of single-walled carbon nanotube; ${ }^{3}$ SVP indicates the saturated vapor pressure at room temperature. 
Here, we only review the sensors operated as transistors with source, drain and gate electrodes and with organic polymer as the semiconducting layer. There are usually four transistor configurations for sensor applications, as shown in Figure 1 [40]. Bottom gate/bottom contact (BGBC) and bottom gate/top contact (BGTC) are mostly applied in the OFET sensors while top gate/top contact (TGTC) and top gate/bottom contact (TGBC) are usually used in the metal-oxide-semiconductor field-effect transistor (MOSFET) sensors. It is important to distinguish the layer (sensing layer) that interacts with gas analytes among polymer semiconducting layer, dielectric layer and conductive polymer gate. According to the sensing layer, the sensors can be further subdivided into three types of sensors, for which this review focuses on the sensing molecules, vapor analytes and sensing performance [41,42]. We have also tried to understand the interactions between sensing polymers and electrically neutral gas analytes, which have aroused the change of source-drain current $\left(I_{\mathrm{SD}}\right)$ in the OFET gas sensors.

a)

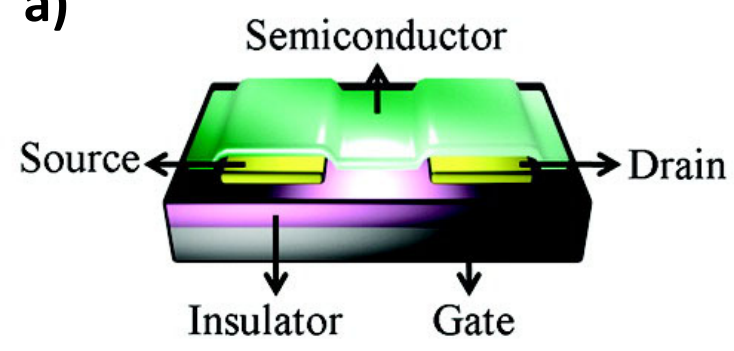

Bottom Gate/Bottom Contact

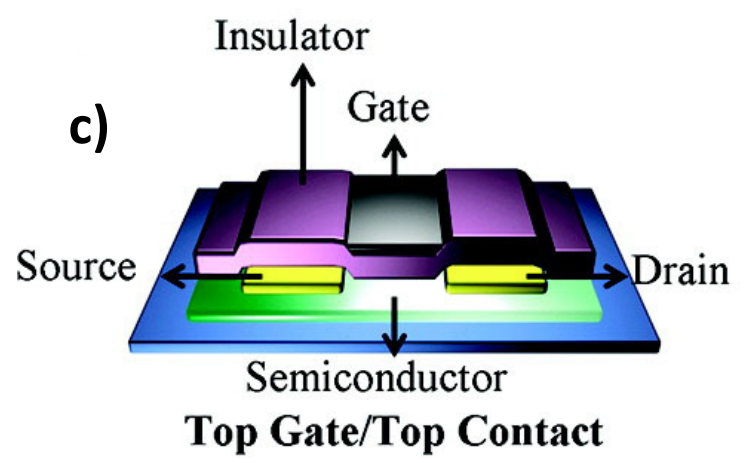

b)

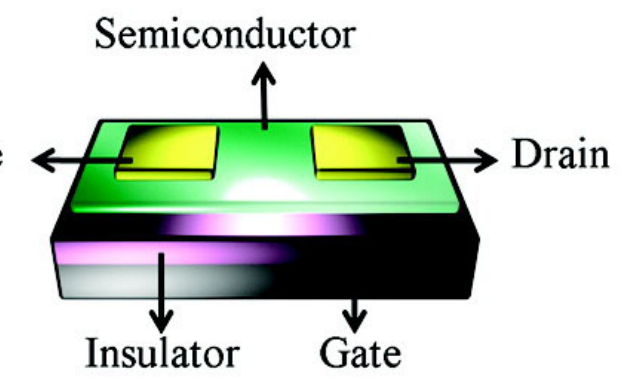

Bottom Gate/Top Contact

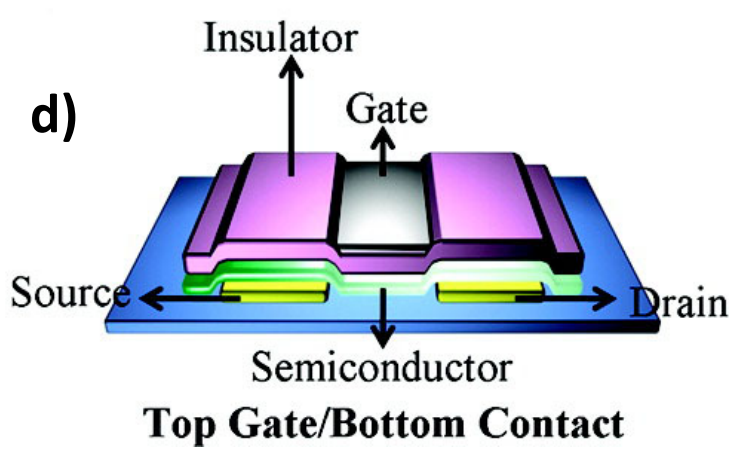

Figure 1. Four types of OFET device structure: (a) bottom gate/bottom contact; (b) bottom gate/top contact; (c) top gate/top contact; and (d) top gate/bottom contact. Reprinted with permission from Ref. [40]. Copyright (2012) American Chemical Society.

\section{Polymer Field-Effect Transistor (PFET) Sensors with Semiconducting Polymers as the Sensing Layer}

The transduction principle of PFET sensors upon exposure to gaseous analytes is ascribed to the change of current at the semiconducting polymer/dielectric interface $\left(I_{\mathrm{SD}}\right)$. The current flowing in the conducting channel can either increase or decrease, which depends on gas-polymer interaction. To date, PFET sensors have been able to detect a wide range of vapors including $\mathrm{NH}_{3}$, amines, $\mathrm{NO}_{2}$, $\mathrm{H}_{2} \mathrm{~S}$, alcohols, etc. Each analyte shows unique response when exposed to PFET devices.

\section{1. $\mathrm{NH}_{3}$ and Amine Gas Sensors}

Ammonia $\left(\mathrm{NH}_{3}\right)$ in air can accelerate the formation of hazy weather, which potentially causes a series of chronic diseases such as asthma, and severe respiratory and lung diseases. Therefore, ammonia detection has attracted great attention and the detection limit has enormously decreased from thousands of ppm to tens of ppb level since first being reported [11]. 
Ammonia usually decreases the flowing current $\left(I_{\mathrm{SD}}\right)$ in the device channel. A semiconducting polymer P-29-DPP-SVS has a hole charge carrier mobility around $3.0 \mathrm{~cm}^{2} \cdot \mathrm{V}^{-1} \cdot \mathrm{s}^{-1}$ which is high enough to achieve pleasant sensitivity [20]. The OFET devices were then fabricated and succeeded in detecting ammonia in the range of 29 to $1000 \mathrm{ppm}$ at a source-drain voltage ( $\left.V_{\mathrm{DS}}\right)$ of $-5 \mathrm{~V}$ and gate voltage $\left(V_{\mathrm{GS}}\right)$ of $-80 \mathrm{~V}$. The lowest detection concentration was $29 \mathrm{ppm}$ which was already much lower than electrical chemiresistor sensors [43]. However, the sensing response toward $29 \mathrm{ppm}$ ammonia is nearly ignorable, which is far from real application. One efficient way to improve the sensitivity is chemical structure adjustment of semiconducting polymer [21]. For example, transformation of ester group (-COOR) into carboxyl group $(-\mathrm{COOH})$ group in the side chain of pDPPCOOH-BT by thermal treatment endows the OFET sensor with good selectivity toward ammonia and amines. The transformation process also accompanies the formation of nanopores in the thin film. The - $\mathrm{COOH}$ group and the porous structure make the detection limit go down to $10 \mathrm{ppb}$ at $V_{\mathrm{DS}}=-60 \mathrm{~V}$ and $V_{\mathrm{GS}}=-80 \mathrm{~V}$, which is low enough for regular detection.

Mixing P3HT semiconductor and polystyrene (PS) dielectric created more interfaces to interact with ammonia (Figure 2), which improved analyte-polymer interaction and lowered the detection limit down to $5 \mathrm{ppm}$ at $V_{\mathrm{DS}}=V_{\mathrm{GS}}=-40 \mathrm{~V}$ [22]. The formed P3HT/PS interfaces also made the sensor have superior stability with very little decrease of sensing response even stored in the atmospheric environment for 40 days. Modification on device structure can improve the sensor sensitivity. An interesting work is to replace the gate electrode and dielectric with the introduction of static charges on the back surface of the electret polyethylene terephthalate (PET) substrate by corona charging. This device fabrication process is herein simplified and potentially adaptable to roll-to-roll processing. With $V_{\mathrm{DS}}=-90 \mathrm{~V}$ and static gate induced by corona charging, poly(3,3'-didodecylquaterthiophene) (PQT-12) sensor based on this device structure gave a reasonable detection limit of $100 \mathrm{ppb}$ [23]. Vertical transistor, whose current flows through the bulk region in the vertical channel, creates improved interaction between gas analyte and conducting channel. In comparison with P3HT sensor based on traditional transistor (horizontal channel), $\mathrm{NH}_{3}$ detection with this device structure obtained a much higher sensitivity with low detection limit of $30 \mathrm{ppb}$ and a low operating voltage around $1 \mathrm{~V} \mathrm{[12].}$ Low-voltage operation is required for sensor application in wireless transducer system and portable devices [24].

a)

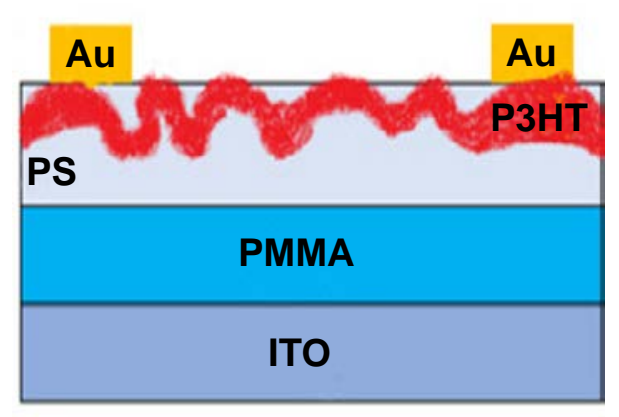

b)

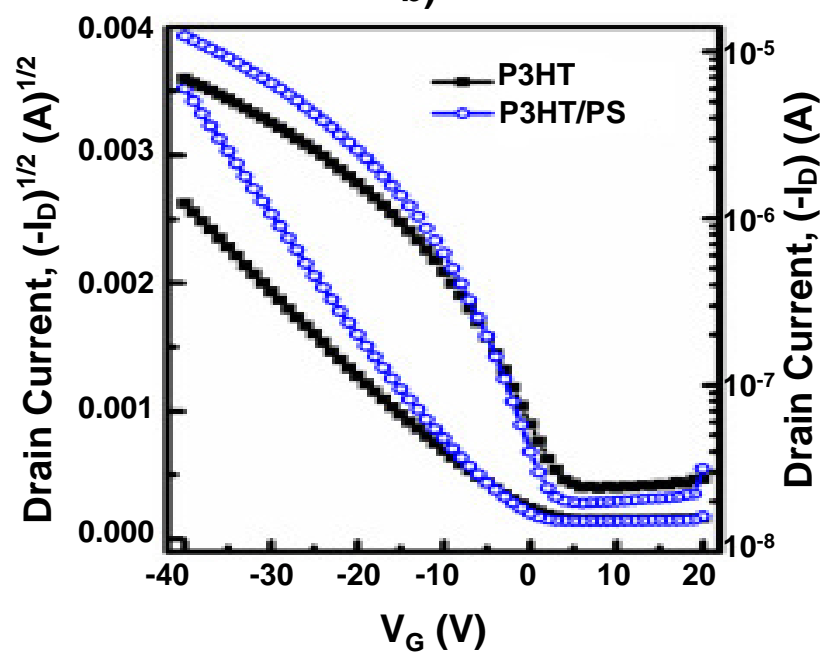

Figure 2. (a) Schematic structure of OFET sensor with poly(3-hexylthiophene)/polystyrene (P3HT/PS) blended film; and (b) transfer curve of P3HT/PS film with the best mixing ratio of 1:4 in weight. Reprinted with permission from Ref. [22]. Copyright (2016) Elsevier. 
Amine detection has potential application in food inspection, for instance, putrescine (butane-1,4-diamine) and cadaverine (pentane-1,5-diamine) are salient markers of meat decomposition but discrimination among different amines is hard to realize [44,45]. In contrast to much attention put on ammonia detection, only a few studies are related to amine detection. Besides ammonia, the $-\mathrm{COOH}$ group attached on the polymer pDPPCOOH-BT mentioned above also showed good sensitivity toward three amines of 1,4-diaminobutane, Et3N and piperidine, but no discrimination among them [21]. Grazing incidence X-ray diffraction (GIXD) proves that longer side chains result in larger plane spacing in the polythiophene thin films [27]. It is found that longer chains have no dependence on film thickness and usually display stronger response since an analyte can penetrate easily into the polythiophene film. As the side chains shorten, dependence on film thickness increases, especially when the length of the side chain becomes comparable to the size of analyte, usually with 4-5 carbons in the polythiophene chain. By varying side chains of the polythiophene molecule as well as the thickness of the polythiophene films, amines with different molecular size can be differentiated. Sensor array employed permutations between two different side chain lengths (poly-3-butylthiophene and poly-3-octylthiophene) and two different film thicknesses (70 nm and $140 \mathrm{~nm}$ ) discriminated hexylamine and trimethylamine, which had different molecular size.

A good understanding of the sensing mechanism is not only important, but may also enable guidelines for modifying and improving sensor performance. Generally, the interaction between gas analyte and sensing layer changes the charge distribution at the semiconductor/dielectric interface. The interaction is always different between various gas analytes and sensing layers and there has been no instruction to predict the analyte-polymer interaction until now. For the tested semiconducting polymers, such as P3HT and its derivatives, PQT-12, pDPPCOOH-BT and so on, ammonia always reduces the current flowing in the conducting channel. The current reduction $\left(\Delta I_{\mathrm{SD}}\right)$ is generally attributed to lone pair of electrons of ammonia which influences the charge transport in two aspects: (1) form linkage type structure with organic molecule as shown in Scheme 2 when $\mathrm{NH}_{3}$ diffuses in the thin film, which causes current decrease in the conducting channel [13]; and (2) trap/dedope at the polymer semiconductor/dielectric interface which negatively shifts the threshold voltage $\left(\Delta V_{\mathrm{T}}\right) . \mathrm{NH}_{3}$ dedopes the P3HT film to compensate the ambient oxidant in P3HT film, which has been confirmed in the purification process of synthesized P3HT [13]. Trapping effect of $\mathrm{NH}_{3}$ is verified through gas exposure toward P3HT/PS mixture in the film. The mixed film has much P3HT/PS interface and blocks $\mathrm{NH}_{3}$ diffusion into the $\mathrm{P} 3 \mathrm{HT} /$ dielectric (PMMA) interface, which results in nearly no $V_{\mathrm{T}}$ shift [22].
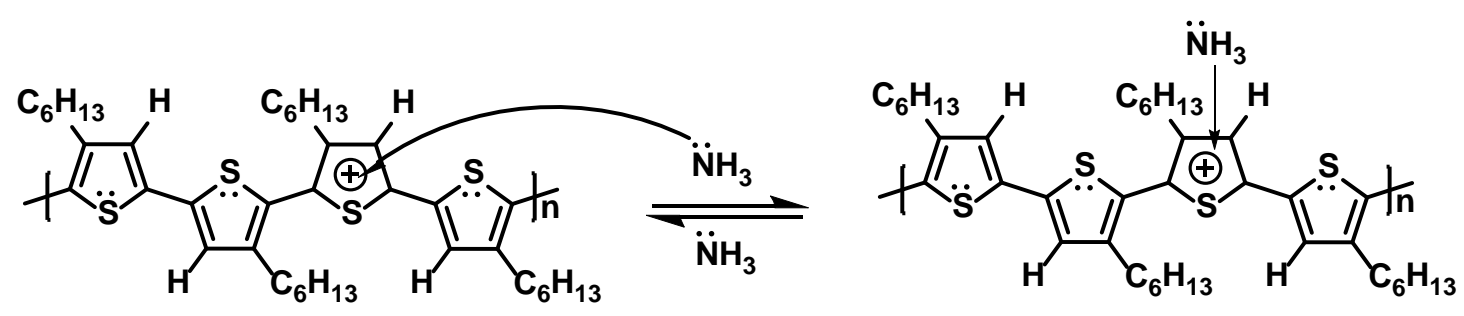

Scheme 2. Formation of linkage type structure between $\mathrm{NH}_{3}$ and P3HT.

Designed functional groups in a polymer molecule play an important role when interacting with gas analyte. The sensing ability of pDPPCOOH-BT OFET sensor is attributed to the $-\mathrm{COOH}$ group. Upon exposure to $\mathrm{NH}_{3}$, FT-IR signal at $1729 \mathrm{~cm}^{-1}$, absorption peak of the $-\mathrm{COOH}$ group in pDPPCOOH-BT, was shifted to $1650 \mathrm{~cm}^{-1}$, indicating the formation of ammonium carboxylate which might act as additional traps for charge carriers [21].

There are only a few reports illustrating the interaction between amines and semiconducting polymers. In one study, it is proven that the sensitivity correlates with the molecular volume of amines, which means that larger amines having poor diffusion into the polymer/dielectric interface [27]. 
They present a framework to describe the analyte concentration from film surface to semiconducting polymer/dielectric interface (Figure 3). In this framework, all factors affecting the analyte concentration are considered. Analyte concentration at the film surface $\left(C_{A}(0)\right)$ is a function of the partition coefficient $\left(\kappa_{\mathrm{PT}}\right)$ of the sensor film, ambient temperature $(K)$ and analyte pressure $(P)$. Then analytes diffuse into the film until they reach the conducting channel at the semiconducting polymer/dielectric interface. It is the concentration of analyte at this interface, $C_{\mathrm{A}}(x=\mathrm{T})$, that gives rise to the electrical response of the sensor. This concentration is dependent on the film thickness $(T)$ and the diffusion coefficient $\left(D_{\mathrm{A}}\right)$ of the analyte. The diffusion coefficient $D_{\mathrm{A}}$ encapsulates the effect of film structure, which is a function of analyte size relative to crystalline plane spacing in the film. In another report, X-ray reflectivity (XRR) monitored the poly-3-butylthiophene film swelling under butylamine exposure [46]. This indicates that the film can adsorb analytes and leads to thickness increase [14]. Though the thickness increase is lower than the electrical response, the physical swelling should be included in the sensing mechanisms just like trapping, dedoping and so on.

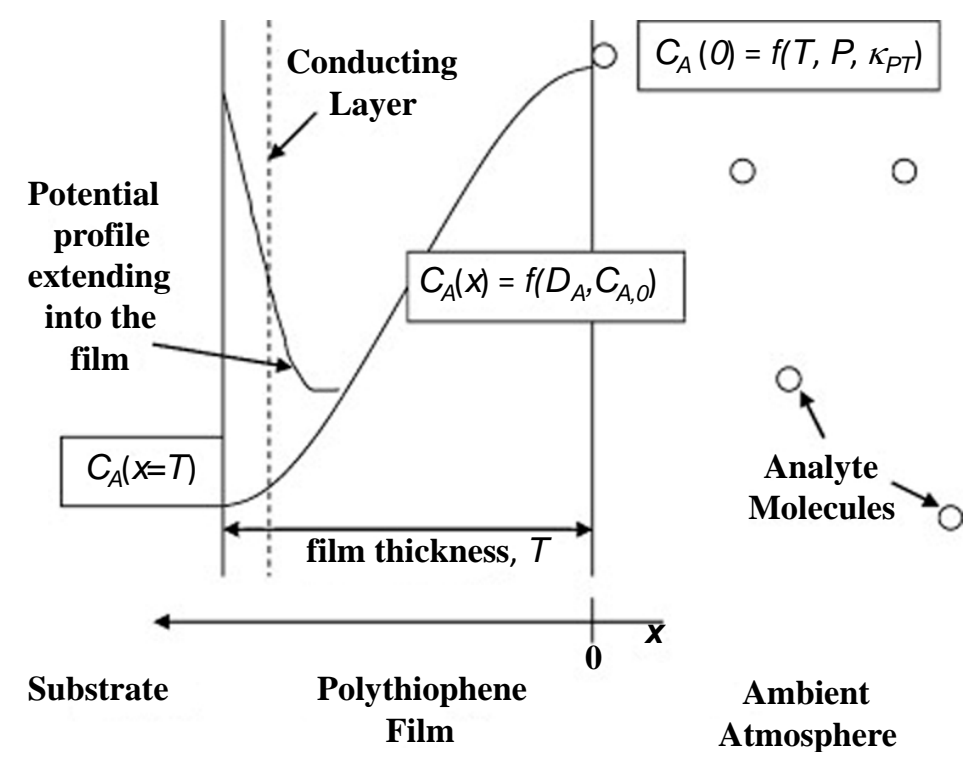

Figure 3. Conceptual framework for physical discrimination. Partial analyte molecules in the ambient atmosphere will adsorb onto the surface of the polythiophene film at $x=0$ and diffuse into the film toward the substrate, eventually interacting with the semiconductor layer at the dielectric-semiconductor interface. Reprinted with permission from Ref. [27]. Copyright (2010) Elsevier.

\section{2. $\mathrm{NO}_{2}$ Gas Sensor}

Many studies report on $\mathrm{NO}_{2}$ gas sensors. The achieved sensitivity is impressive with the lowest detection limit down to $10 \mathrm{ppb}$ [28]. Contrary to ammonia sensor, the $\mathrm{NO}_{2}$ gas sensor usually increases the flowing current in the device channel $[16,28]$. Figure 4 displays the output and transfer characteristics of PTA-OMe OFETs without gas exposure (Figure 4a) and with gas exposure of $10 \mathrm{ppm}$ $\mathrm{NO}_{2}$ at $V_{\mathrm{SD}}=V_{\mathrm{GS}}=-3 \mathrm{~V}$ (Figure $\left.4 \mathrm{~b}\right)$. There is a clearly nonlinearity of the output characteristic at low source-drain voltage $\left(V_{\mathrm{SD}}\right)$ in the pristine device. After exposure to $10 \mathrm{ppm} \mathrm{NO}_{2}$, the output characteristics turned linear at low $V_{\mathrm{SD}}$ and unsaturated at high $V_{\mathrm{SD}}$, indicating the existence of doping at the contact as well as in the channel. The transfer curve shows the threshold voltage shifted toward positive direction under $\mathrm{NO}_{2}$ exposure. The supposed interaction between $\mathrm{NO}_{2}$ and PTA-OMe is shown in Scheme $3[16,47]$. In this experiment, semiconducting PTA-OMe was amorphous and had low carrier mobility of around $10^{-5} \mathrm{~cm}^{2} \cdot \mathrm{V}^{-1} \cdot \mathrm{s}^{-1}$ due to absence of crystalline grain boundary. It is not $\mu$ but $V_{\mathrm{T}}$ is more sensitive to $\mathrm{NO}_{2}$ gas, which tells the advantage of multi-parameter OFET sensor. 

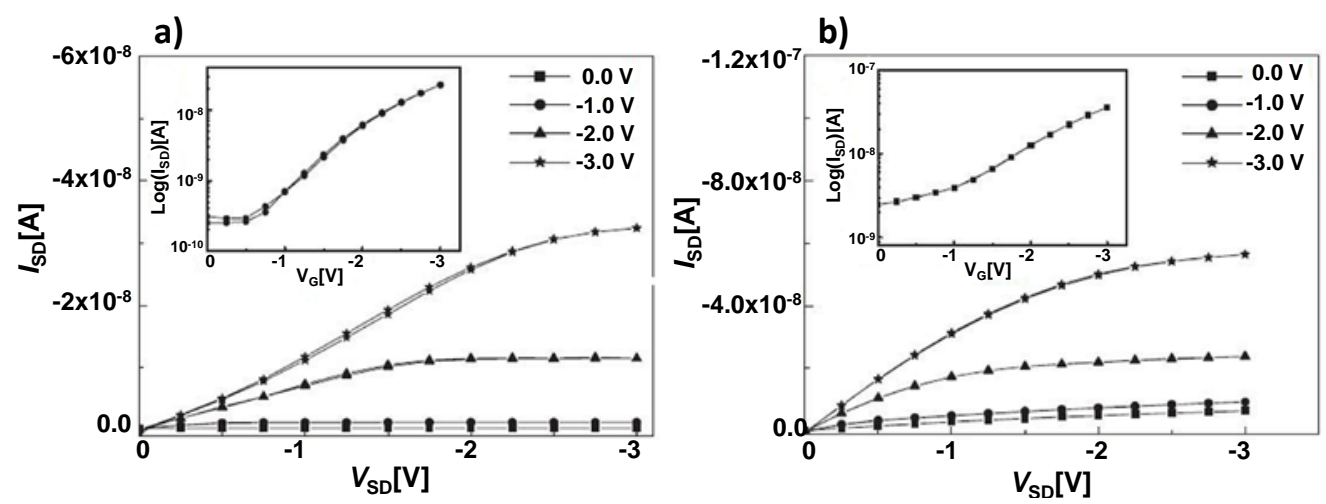

Figure 4. Output curves of PTA-OMe OFETs: (a) before $\mathrm{NO}_{2}$ exposure; and (b) after $\mathrm{NO}_{2}$ exposure. The insets show saturated transfer curves of the corresponding OFETs in semilog plots. Reprinted with permission from Ref. [28]. Copyright (2007) Wiley-VCH.
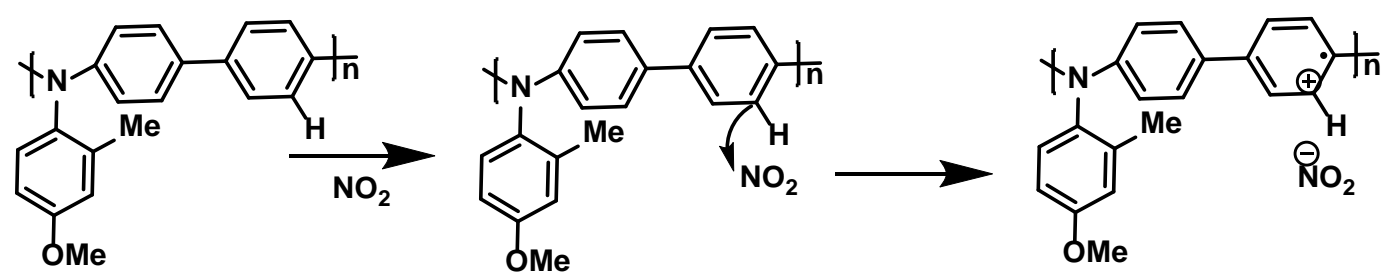

Scheme 3. Proposed interaction between $\mathrm{NO}_{2}$ and polymer semiconductor PTA-OMe.

With the same molecular backbone but different substituents in the side chain, PTA-OMe showed higher sensitivity than PTA-F while PTA-F had much shorter recovery time than PTA-OMe. If more attention were paid to the substituents, sensors with high sensitivity as well as fast response are realizable.

\subsection{Alcohol Sensor}

Many alcohol sensors based on pure polymer OFETs have been reported but the sensing response is usually low with detection limit of around thousands of ppm. The sensitivity can be greatly increased by mixing the semiconducting polymer with functionalized graphene oxide (GO) [29,30]. An OFET sensor with mixture of polymer F8T2 and oleylamine-modified GO (OA-GO) as the sensing layer was investigated [30]. In contrast to the pure F8T2, the mixture showed sensitivity 10 times higher in $\% \Delta V_{\mathrm{T}}$ and six times higher in $\% \Delta \mu$ with respect to ethanol under the same applied voltage of $V_{\mathrm{DS}}=V_{\mathrm{GS}}=-80 \mathrm{~V}$. The functionalized GO in the composite film helped to adsorb the gas analyte for one side and increased the surface-to-volume ratio for the other side. Moreover, the content of GO in the mixed film should be carefully controlled and the optimal content was determined to be $1 \%$ $(\mathrm{w} / \mathrm{w})$ [29].

Polymer FET sensors toward alcohols pay much attention on sensing mechanism. Many valuable conclusions have been achieved: (1) Sensing response is related with alcohol molecular volume which affects the analyte diffusion into the polymer film [39]. Alcohol with smaller molecular volume will be easier to diffuse into the film. (2) Polar-type interaction dominates in polar-polymer (for example, Poly-DPOT with alkoxy chain) sensor which makes the device more sensitive toward polar alcohols. On the other hand, dispersion-type interaction is recognized in non-polar-polymer (for example, Poly-DDT with alkyl chain) sensor which is more sensitive to long alkyl chain-bearing alcohols [31,32]. (3) Alcohols can trap the hole charge carriers in the channel region due to the lone electron pair in the hydroxyl group $(-\mathrm{OH})[17,30,34]$. The negative shift of threshold voltage is ascribed to the deep trap states induced by the hydroxyl group in the alcohols. The mobility decrease $(\Delta \mu)$ is more 
easily interrupted by shallow trap density generated from weak interaction between gas analytes and polymers. Both deep trap and shallow trap states can be erased by desorption of gas analytes [29].

\subsection{Other Gas Sensors}

$\mathrm{H}_{2} \mathrm{~S}$ is a toxic and flammable gas with a characteristic odor of rotten egg. Concentration of $\mathrm{H}_{2} \mathrm{~S}$ is usually lower than $1 \mathrm{ppb}$ in unpolluted areas and $5 \mathrm{ppb} \mathrm{H}_{2} \mathrm{~S}$ for long-time exposure can induce adverse health effects including respiratory, eye and nasal problems. Little work has been carried out on $\mathrm{H}_{2} \mathrm{~S}$ gas sensors but one excellent OFET sensor based on spiro-annulated polymer PSFDTBT is reported by Lv and her coworkers [33]. In this work, the $\mathrm{H}_{2} \mathrm{~S}$ sensor exhibited high sensitivity, excellent selectivity, fast response, and good operational stability. Under applied voltage of $V_{\mathrm{DS}}=V_{\mathrm{GS}}=-30 \mathrm{~V}$, the lowest concentration that could be detected was only $1 \mathrm{ppb}$, at which the current decrease $\left(\Delta I_{S D}\right)$ was still $35 \%$ high. Polymer PSFDTBT device is to date the most sensitive $\mathrm{H}_{2} \mathrm{~S}$ sensor based on organic semiconducting film. Investigation on the sensing process shows that the sensitivity is greatly related with the film thickness. The sensitivity increases first and then decreases as polymer films become thinner. Further experiment proves that, by thinning the active layer, both analyte adsorption and desorption speeds increase but desorption speed rises faster than the adsorption speed (Figure 5). The optimized film thickness is found to be $20 \mathrm{~nm}$.

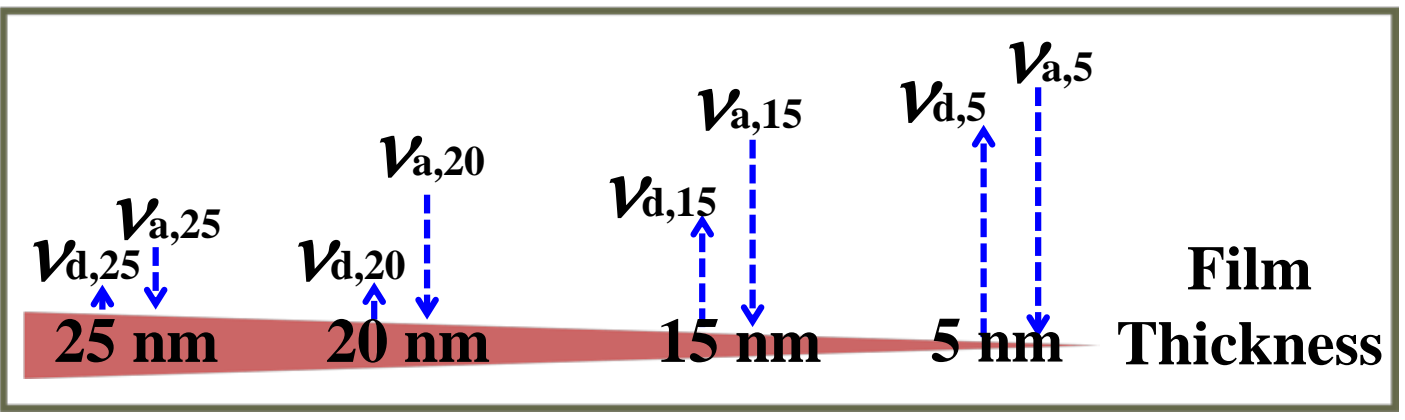

Figure 5. The supposed sensing process of $\mathrm{H}_{2} \mathrm{~S}$ in film of polymer PSFDTBT. Both adsorption and desorption speeds of $\mathrm{H}_{2} \mathrm{~S}$ molecules increase when the polymer films become thinner. However, desorption speed $\left(v_{\mathrm{d}, \mathrm{n}} ; \mathrm{n}=25,20,15\right.$, and $\left.5 \mathrm{~nm}\right)$ increases much faster than adsorption speed $\left(v_{\mathrm{a}, \mathrm{n}}\right)$. The length of arrows denotes the level of the speed.

Nitro based explosive gases, e.g., 1,3,5-trinitro-1,3,5-triazacyclohexane (RDX), 2,4,6-trinitrotoluene (TNT), and dinitrobenzene (DNB), were successfully detected by a ternary composite film of P3HT, CuTPP (CuII tetraphenylporphyrin) and ADB (copolymer of diethynyl-pentiptycene and dibenzyl-ProDOT) as shown in Scheme 4 [35]. This sensor showed ignorable response toward non-explosive nitro based gases like nitrobenzene (NB), benzoquinone (BQ) and benzophenone (BP), indicating an excellent selectivity for nitro based explosive analytes such as TNT, RDX, DNB. Even $10 \mathrm{ppb}$ TNT gas gave an obvious current increase $\left(-\Delta I_{\mathrm{SD}}\right)$ of around $18 \%$ at $V_{\mathrm{DS}}=-40 \mathrm{~V}$ and $V_{\mathrm{GS}}=-20 \mathrm{~V}$. In this ternary film, compound $\mathrm{ADB}$ makes the film porous and rough which eventually increases the surface-to-volume ratio; CuTPP can form a coordinate bonding between the metalloporphyrin molecule and the nitro group [48] as well as the $\pi$-stacking between the porphyrins and the aromatic rings from P3HT polymer. The strong interaction between electron deficient RDX, TNT and DNB gases and electron rich porphyrin macrocycle improves the film conductance, which should be responsible for the high sensitivity toward explosive nitro based gases. 2,3-dimethyl-2,3-dinitrobutane (DMNB), which is usually blended with commercial explosives, is used as a detection taggant for explosives. OFET sensors based on the semiconducting polymer PBTTT were able to detect $6.5 \mathrm{ppm}$ DMNB. After exposure to DMNB gas, the source-drain current shows an obvious increase. Additionally, the largest current increase $\left(-\Delta I_{\mathrm{SD}}\right)$ is $36.5 \%$ at $V_{\mathrm{DS}}=-100 \mathrm{~V}$ 
and $V_{\mathrm{GS}}=-53 \mathrm{~V}$ [26]. Interaction between DMNB and PBTTT has not been clearly explained in this experimental work and more work should be carried to understand the sensing mechanism.
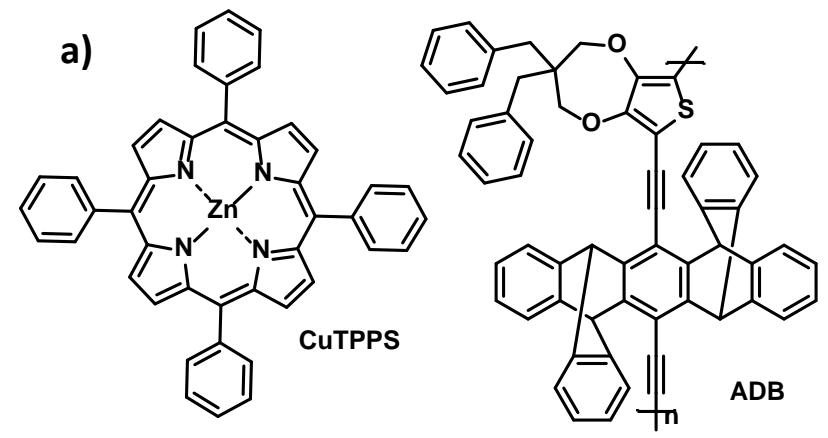

c)<smiles>O=[N+]([O-])N1CN([N+](=O)[O-])C[N+]([N+](=O)[O-])C1</smiles><smiles>Cc1c([N+](=O)[O-])cc([N+](=O)[O-])cc1[N+](=O)[O-]</smiles>

TNT b)<smiles>O=C1C=CC(=O)C=C1</smiles>

d)<smiles>CC(C)([N+](=O)[O-])C(C)(C)[N+](=O)[O-]</smiles>

Scheme 4. Chemical structures of: (a) compounds CuTPPS (CuII tetraphenylporphyrin) and ADB (copolymer of diethynyl-pentiptycene and dibenzyl-ProDOT); (b) non-explosive and (c) explosive nitro-based gas analytes; and (d) 2,3-dimethyl-2,3-dinitrobutane (DMNB).

Dimethyl methylphosphonate (DMMP) OFET sensor is just mentioned in a report about chemiresistor sensor $[36,49]$. In this Experiment, the mixture of hexafluoroisopropanol substituted polythiophene (HFIP-PT) and single-walled carbon nanotube acted as the sensing layer. Under exposure of DMMP saturated vapor gas, the source-drain current $\left(I_{S D}\right)$ reduced and the threshold voltage shifted negatively. No more discussions on OFET sensor are presented in this work. $\mathrm{CHCl}_{3}$ gas was under detection of poly(3-butylthiophene) based OFET sensor, where $\mathrm{CHCl}_{3}$ proved to increase the flowing current in the channel [37]. There are no discussions on the sensing process and therefore much more work is needed to clarify the interaction between $\mathrm{CHCl}_{3}$ gas and semiconducting polymer.

Even structurally similar isomers can be differentiated through use of multi-parameter. Xylene, including three isomers which are $o$-xylene, $m$-xylene and $p$-xylene, impair the human respiratory system, the central nervous system, liver, kidneys, eyes, and skin. An OFET sensor based on an ambipolar semiconducting polymer PDPPHD-T3 could detect and discriminate the three xylene isomers at $40 \mathrm{ppm}$ with applied voltages of $V_{\mathrm{SD}}=-70 \mathrm{~V}$ and $V_{\mathrm{GS}}=-60 \mathrm{~V}$ [38]. Upon exposure to the three xylene isomers, both the hole mobility $\left(\mu_{\mathrm{h}}\right)$ and electron mobility $\left(\mu_{\mathrm{e}}\right)$ decreased. Based on the measured transfer curve, multi sensing parameters which were changes in hole voltage threshold $\left(\Delta V_{\text {th-h }}\right)$, normalized changes in the hole mobility $\left(\Delta \mu_{\mathrm{h}} / \mu_{\mathrm{hb}}\right)$, hole subthreshold swing $\left(\Delta S S_{\mathrm{h}}\right)$, changes in the electron voltage threshold, $\left(\Delta V_{\text {th-e }}\right)$, normalized changes in the electron mobility $\left(\Delta \mu_{\mathrm{e}} / \mu_{\mathrm{eb}}\right)$ and electron subthreshold swing $\left(\Delta S S_{\mathrm{e}}\right)$ were calculated. Three xylene isomers could then be clearly distinguished from each other using a principle component analysis (PCA) plot of six sensing parameters in response to different xylene isomers at $40 \mathrm{ppm}$. DFT calculation shows that both HOMO and LUMO energies increase after adsorption of xylene isomers. This indicates a decrease in the hole-injection barrier and increase in the electron-injection barrier, which agrees well with the experimental sensing response of PDPPHD-T3 toward xylene isomers. Additionally, swelling of the polymer film induced by the adsorption of the xylene isomers affects the change of the sensing parameters. FTIR spectroscopy has experimentally monitored the shift of stretching vibrations including $\mathrm{C}=\mathrm{O}, \mathrm{C}-\mathrm{N}, \mathrm{C}=\mathrm{C}, \mathrm{C}-\mathrm{C}$ and $\mathrm{C}-\mathrm{H}$ bonds, proving the complexes of $\mathrm{PDPPHD}-\mathrm{T} 3$ polymer and xylene isomers. 
Due to the advantage of multi-parameter extracted from transfer characteristics, transistor sensors can diagnose more than one analyte at the same time. Multi-parameter data provide a rich source of sensing information and can reveal the non-obvious features of weak interaction between gas analytes and polymer semiconductors. A PTA-OMe sensor has recorded the change of four parameters $V_{\mathrm{T}}, \mu$, $I_{\mathrm{ON}}, I_{\mathrm{OFF}}$ at $V_{\mathrm{GS}}=V_{\mathrm{DS}}= \pm 2.5 \mathrm{~V}$ when the transistors are under exposure of different alcohols [34]. The PTA-OMe had a quite low hole mobility around $5 \times 10^{-5} \mathrm{~cm}^{2} \cdot \mathrm{V}^{-1} \cdot \mathrm{s}^{-1}$ and a weak response toward alcohols. However, with the four measured parameters, sensing performance of four tested alcohols (methanol, ethanol, 1-propanol and isopropanol) could be discriminated. Sensor arrays with integrated OFET sensors show much better performance. For example, an array comprising four sensors with permutations of $70 \mathrm{~nm}$ and $140 \mathrm{~nm}$ film thicknesses and polybutylthiophene and polyoctylthiophene were fabricated [27]. This array could differentiate the mixtures of triethylamine and hexylamine by measuring the variation of $V_{\mathrm{T}}, I_{\mathrm{SD}}$, and $\mu$. Another integrated sensor array, composed of five polymers with complementary sensing response by incorporating functional groups into the molecules, was fabricated by inkjet printing method [39]. Twelve gas analytes were exposed to this sensor array and the response was summarized in Figure 6 , in which three parameters $\left(\Delta I_{\mathrm{SD}}, \Delta \mu\right.$, and $\Delta V_{\mathrm{T}}$ ) were recorded. The differential response of multi-parameter makes these OFETs attractive for use in electronic nose.

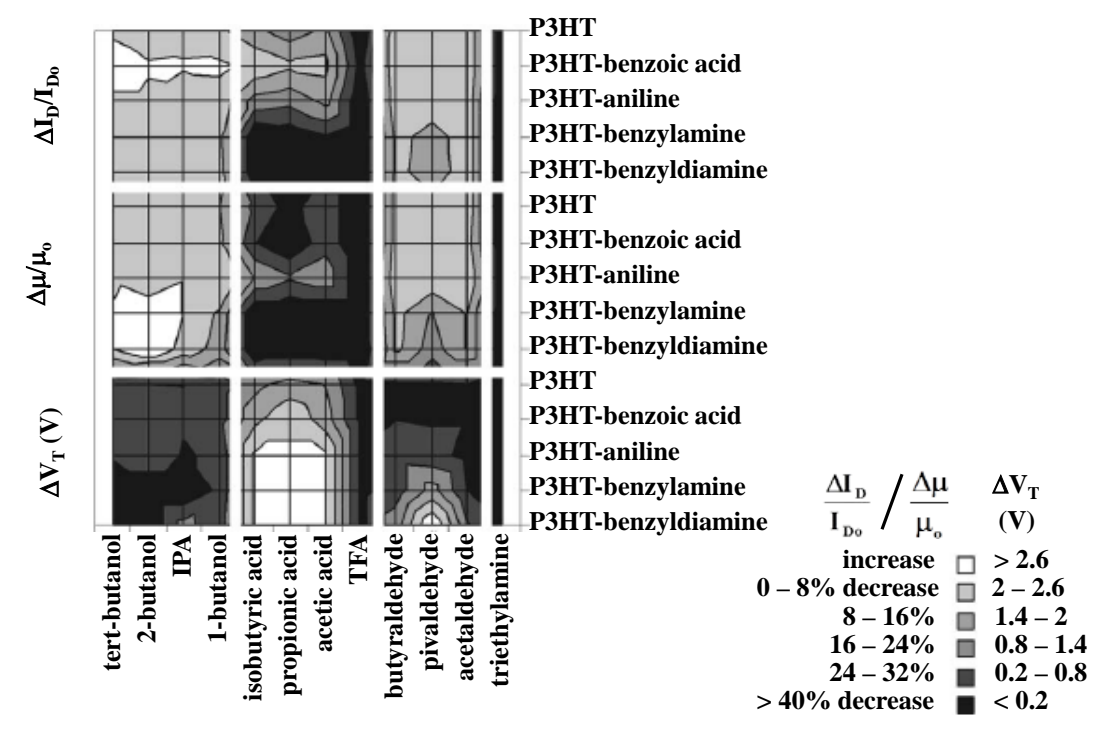

Figure 6. Response of five polymers toward twelve gas analytes in the sensor array. Baseline is established through operation in ambient conditions, and sensor response is measured after exposure to $40 \mathrm{ppm}$ of each analyte for $2 \mathrm{~min}$. Reprinted with permission from Ref. [39]. Copyright (2006) American Institute of Physics.

Existence of water vapor in the ambient environment is inevitable. In order to realize the application of OFET sensor out of lab condition, it is important to study the water vapor effect toward OFET sensor. Most of the reported sensing polymer semiconductors have good air stability and show ignorable effect toward water vapor $[13,14,22,33,50]$. However, the water effect should be minimized so that a pure analyte effect can be achieved. For example, $60 \%$ RH in air and $85 \%-90 \%$ RH in water vapor were studied before exposure of ammonia to the P3HT OFET device [13]. The source-drain current showed a little increase. To get pure ammonia gas effect, this water effect was then eliminated by subtracting the net current difference in air $(60 \% \mathrm{RH})$ and in water vapor $(85 \%-90 \% \mathrm{RH})$. In addition, mixing P3HT with polystyrene also greatly improved the device stability by preventing the water from diffusing into the dielectric/semiconductor directly [22]. The most important factor to minimize the water effect is the air stability of OFET device, which can be enhanced by modification of self-assembled monolayer on dielectric layer and usage of air-stable sensing semiconductors [8]. 


\section{PFET Sensors with Dielectric Layer as Sensing Layer}

Analyte exposure upon an OFET changes the source-drain current flowing in the first few monolayers above the dielectric/semiconducting polymer interface. Therefore, direct functionalization on the dielectric layers efficiently controls the sensing response, which further proves the interaction between gas analytes and semiconducting polymer/dielectric interface. In an OFET sensor, the dielectric layer can influence the sensing response from two sides: (1) film morphology of semiconducting polymer related to analyte adsorption; and (2) the flowing current in the conducting channel by the analyte/dielectric interaction. Moreover, current increase or decrease induced by the same gas analyte is dependent on the dielectric/semiconducting polymer interface [18,51,52].

Morphology optimization of polymer semiconductors greatly enhances their sensing response toward gas analytes [25]. Polymer PBTTT was separately spin-coated onto three kinds of surfaces that were bare, octyltrichlorosilane (OTS) and CYTOP modified $\mathrm{SiO}_{2} / \mathrm{Si}$ surface. After $\mathrm{NH}_{3}$ exposure, PBTTT film on OTS, with the highest film crystallinity among the three dielectrics, exhibited apparently the largest current decrease. Optimal film morphology to achieve both high surface-to-volume ratio and high mobility charge carrier is important in good gas sensing characteristics.

Siloxane layer (T-SC/SA) bound with sulfonic acid group was modified onto the $\mathrm{SiO}_{2} / \mathrm{Si}$ surface (Scheme 5a) [19]. In a BGTC structured device, the sulfonic acid group protonated the semiconducting P3HT and resulted in high positive $V_{\mathrm{T}}$ of up to $45 \mathrm{~V}$. Under exposure to alkaline amines, the positive $V_{\mathrm{T}}$ showed negatively shift of about $60 \mathrm{~V}$ due to the deprotonation effect of the alkaline amines. In contrast, a negative shift of $V_{\mathrm{T}}$ was only $10 \mathrm{~V}$ for the bare $\mathrm{SiO}_{2} / \mathrm{Si}$ dielectric and was around $30 \mathrm{~V}$ for n-hexadecyltrichlorosilane (HDTS) $/ \mathrm{SiO}_{2} / \mathrm{Si}$ dielectric. The huge electric response of T-SC $/ \mathrm{SA}$ to alkaline amines holds high promise for its applications in chemical sensors. Ring-opening metathesis polymerized (ROMP, Scheme $5 b$ ) dielectric materials exhibited similar effect as T-SC/SA dielectric and TGBC structure was used in this study [15]. When exposed to ammonia, the -OH group of ROMP dielectric could be deprotonated and thus formed mobile ammonium ions $\left(\mathrm{NH}_{4}^{+}\right)$. Under applied voltage, the mobile $\mathrm{NH}_{4}{ }^{+}$ions could move within the dielectric materials toward drain electrode and localized near the dielectric/P3HT interface or even in the P3HT layer. Hence, the density of mobile charge carriers in the channel was increased by the protonated $\mathrm{NH}_{3}$ by the ROMP dielectric layer.

a)

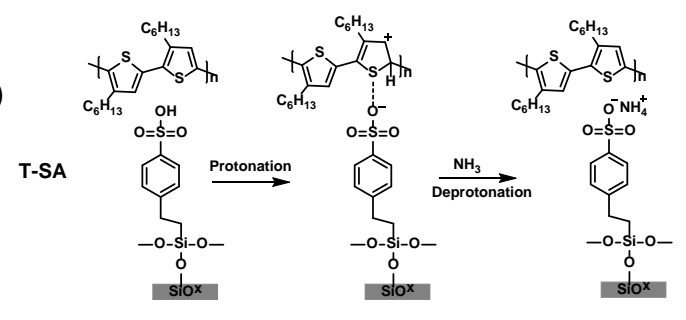

b)

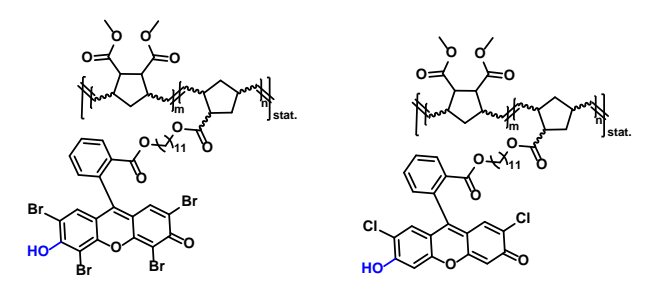

Scheme 5. (a) Proposed sensing mechanism with siloxane (T-SA) modified dielectric as the sensing layer; and (b) chemical structures of ROMP-dielectric materials: (left) statistic co-polymer with eosin $\mathrm{Y}$ as $\mathrm{NH}_{3}$-sensitive group $(\mathrm{m}=300, \mathrm{n}=3)$, and (right) statistic co-polymer with 2,7-dichlorfluorescein as $\mathrm{NH}_{3}$-sensitive group $(\mathrm{m}=300, \mathrm{n}=3)$.

Metal gate could be replaced with conducting polymer sensing layer, usually in a MOSFET sensor. Much work on conducting polymer gate FETs for vapor sensing has been reported. There are already a few reviews to summarize this topic [53-55]; therefore, we will not further discuss them here. 


\section{Conclusions and Future Perspectives}

This review summarizes the PFET sensors categorized by sensing layers consisting of semiconducting layer, dielectric layer and conducting gate layer, separately, with the focus on sensing polymers, gas analytes, sensor performance and sensing mechanism. OFETs with polymers as the semiconducting layer have been demonstrated as effective sensors in gas detection. Although discussions on analyte-polymer interaction have been addressed, there is still a lack of systematic rules to predict and instruct the fabrication of OFET sensors. More gas analytes and sensing polymers need to be introduced, which will enrich the sensing database and help to understand the sensing mechanism. OFET sensor array is able to analyze complex analytes and is a promising area in the future. Furthermore, humidity in the air can impair the OFET sensor and this effect should be minimized. Although calibration of sensor measurements by subtracting the humidity effect at various humidity levels is available, improving the stability of sensing polymers is the most efficient approach, and needs much more investigation. Other approaches including mixing sensing polymer semiconductors with dielectrics and modifying the dielectric layers with self-assembled layers should also be developed.

Acknowledgments: This work was funded by the Germany-China Joint Project TRR61 (DFG-NSFC Transregio Project), the National Natural Science Foundation of China (91227201, 21527805) and Suzhou Industrial Park (SUN-WIN project 2013).

Author Contributions: Lifeng Chi conceived and instructed this work. Aifeng Lv wrote this manuscript. Yong Pan helped to modify this manuscript with his professional background.

Conflicts of Interest: The authors declare no conflict of interest.

\section{References}

1. Mabeck, J.T.; Malliaras, G.G. Chemical and biological sensors based on organic thin-film transistors. Anal. Bioanal. Chem. 2006, 384, 343-353. [CrossRef] [PubMed]

2. Locklin, J.; Bao, Z.N. Effect of morphology on organic thin film transistor sensors. Anal. Bioanal. Chem. 2006, 384, 336-342. [CrossRef] [PubMed]

3. Wang, L.; Fine, D.; Sharma, D.; Torsi, L.; Dodabalapur, A. Nanoscale organic and polymeric field-effect transistors as chemical sensors. Anal. Bioanal. Chem. 2006, 384, 310-321. [CrossRef] [PubMed]

4. Bartic, C.; Borghs, G. Organic thin-film transistors as transducers for (bio) analytical applications. Anal. Bioanal. Chem. 2006, 384, 354-365. [CrossRef] [PubMed]

5. Roberts, M.E.; Sokolov, A.N.; Bao, Z.N. Material and device considerations for organic thin-film transistor sensors. J. Mater. Chem. 2009, 19, 3351-3363. [CrossRef]

6. Vishinkin, R.; Haick, H. Nanoscale sensor technologies for disease detection via volatolomics. Small 2015, 11, 6142-6164. [CrossRef] [PubMed]

7. Torsi, L.; Dodabalapur, A.; Sabbatini, L.; Zambonin, P.G. Multi-parameter gas sensors based on organic thin-film-transistors. Sens. Actuators B Chem. 2000, 67, 312-316. [CrossRef]

8. Bayn, A.; Feng, X.; Müllen, K.; Haick, H. Field effect transistors based on polycyclic aromatic hydrocarbons for the detection and classification of volatile organic compounds. ACS Appl. Mater. Interfaces 2013, 5, 3431-3440. [CrossRef] [PubMed]

9. Pfister, G. Hopping transport in a molecularly doped organic polymer. Phys. Rev. B 1977, 16, 3676-3687. [CrossRef]

10. Tsao, H.N.; Müllen, K. Improving polymer transistor performance via morphology control. Chem. Soc. Rev. 2010, 39, 2372-2386. [CrossRef] [PubMed]

11. Assadi, A.; Gustafsson, G.; Willander, M.; Svensson, C.; Inganäs, O. Determination of field-effect mobility of poly(3-hexylthiophene) upon exposure to $\mathrm{NH}_{3}$ gas. Synth. Met. 1990, 37, 123-130. [CrossRef]

12. Zan, H.W.; Li, C.H.; Yu, C.K.; Meng, H.F. Sensitive gas sensor embedded in a vertical polymer space-charge-limited transistor. Appl. Phys. Lett. 2012, 101, 023303. [CrossRef]

13. Tiwari, S.; Singh, A.K.; Joshi, L.; Chakrabarti, P.; Takashima, W.; Kaneto, K.; Prakash, R. Poly-3-hexylthiophene based organic field-effect transistor: Detection of low concentration of ammonia. Sens. Actuator B Chem. 2012, 171, 962-968. [CrossRef] 
14. Cavallari, M.R.; Izquierdo, J.E.E.; Braga, G.S.; Dirani, E.A.T.; Pereira-da-Silva, M.A.; Rodriguez, E.F.G.; Fonseca, F.J. Enhanced sensitivity of gas sensor based on poly(3-hexylthiophene) thin-film transistors for disease diagnosis and environment monitoring. Sensors 2015, 15, 9592-9609. [CrossRef] [PubMed]

15. Klug, A.; Denk, M.; Bauer, T.; Sandholzer, M.; Scherf, U.; Slugovc, C.; List, E.J.W. Organic field-effect transistor based sensors with sensitive gate dielectrics used for low-concentration ammonia detection. Org. Electron. 2013, 14, 500-504. [CrossRef]

16. Xie, T.; Xie, G.Z.; Du, H.F.; Zhou, Y.; Xie, F.B.; Jiang, Y.D.; Tai, H.L. The fabrication and optimization of thin-film transistors based on poly(3-hexylthiophene) films for nitrogen dioxide detection. IEEE Sens. J. 2016, 16, 1865-1871. [CrossRef]

17. Lienerth, P.; Fall, S.; Leveque, P.; Soysal, U.; Heiser, T. Improving the selectivity to polar vapors of OFET-based sensors by using the transfer characteristics hysteresis response. Sens. Actuator B Chem. 2016, 225, 90-95. [CrossRef]

18. Sandberg, H.G.O.; Backlund, T.G.; Osterbacka, R.; Jussila, S.; Makela, T.; Stubb, H. Applications of an all-polymer solution-processed high-performance, transistor. Synth. Met. 2005, 155, 662-665. [CrossRef]

19. Pacher, P.; Lex, A.; Proschek, V.; Etschmaier, H.; Tchernychova, E.; Sezen, M.; Scherf, U.; Grogger, W.; Trimmel, G.; Slugovc, C.; et al. Chemical control of local doping in organic thin-film transistors: From depletion to enhancement. Adv. Mater. 2008, 20, 3143-3148. [CrossRef]

20. Ryu, G.S.; Park, K.H.; Park, W.T.; Kim, Y.H.; Noh, Y.Y. High-performance diketopyrrolopyrrole-based organic field-effect transistors for flexible gas sensors. Org. Electron. 2015, 23, 76-81. [CrossRef]

21. Yang, Y.; Zhang, G.X.; Luo, H.W.; Yao, J.J.; Liu, Z.T.; Zhang, D.Q. Highly sensitive thin-film field-effect transistor sensor for ammonia with the DPP-bithiophene conjugated polymer entailing thermally cleavable tert-butoxy groups in the side chains. ACS Appl. Mater. Interfaces 2016, 8, 3635-3643. [CrossRef] [PubMed]

22. Han, S.J.; Zhuang, X.M.; Shi, W.; Yang, X.; Li, L.; Yu, J.S. Poly(3-hexylthiophene)/ polystyrene (P3HT/PS) blends based organic field-effect transistor ammonia gas sensor. Sens. Actuator B Chem. 2016, 225, 10-15. [CrossRef]

23. Besar, K.; Yang, S.; Guo, X.G.; Huang, W.; Rule, A.M.; Breysse, P.N.; Kymissis, I.J.; Katz, H.E. Printable ammonia sensor based on organic field effect transistor. Org. Electron. 2014, 15, 3221-3230. [CrossRef]

24. Chen, D.J.; Lei, S.; Chen, Y.Q. A single polyaniline nanofiber field effect transistor and its gas sensing mechanisms. Sensors 2011, 11, 6509-6516. [CrossRef] [PubMed]

25. Yu, S.H.; Cho, J.; Sim, K.M.; Ha, J.U.; Chung, D.S. Morphology-driven high-performance polymer transistor-based ammonia gas sensor. ACS Appl. Mater. Interfaces 2016, 8, 6570-6576. [CrossRef] [PubMed]

26. Wang, L.; Swensen, J.S. Dual-transduction-mode sensing approach for chemical detection. Sens. Actuator B Chem. 2012, 174, 366-372. [CrossRef]

27. Liao, F.; Yin, S.; Toney, M.F.; Subramanian, V. Physical discrimination of amine vapor mixtures using polythiophene gas sensor arrays. Sens. Actuator B Chem. 2010, 150, 254-263. [CrossRef]

28. Das, A.; Dost, R.; Richardson, T.; Grell, M.; Morrison, J.J.; Turner, M.L. A nitrogen dioxide sensor based on an organic transistor constructed from amorphous semiconducting polymers. Adv. Mater. 2007, 19, 4018-4023. [CrossRef]

29. Cheon, K.H.; Cho, J.; Kim, Y.H.; Chung, D.S. Thin film transistor gas sensors incorporating high-mobility diketopyrrolopyrole-based polymeric semiconductor doped with graphene oxide. ACS Appl. Mater. Interfaces 2015, 7, 14004-14010. [CrossRef] [PubMed]

30. Kim, Y.; An, T.K.; Kim, J.; Hwang, J.; Park, S.; Nam, S.; Cha, H.; Park, W.J.; Baik, J.M.; Park, C.E. A composite of a graphene oxide derivative as a novel sensing layer in an organic field-effect transistor. J. Mater. Chem. C 2014, 2, 4539-4544. [CrossRef]

31. Torsi, L.; Tanese, M.C.; Cioffi, N.; Gallazzi, M.C.; Sabbatini, L.; Zambonin, P.G.; Raos, G.; Meille, S.V.; Giangregorio, M.M. Side-chain role in chemically sensing conducting polymer field-effect transistors. J. Phys. Chem. B 2003, 107, 7589-7594. [CrossRef]

32. Torsi, L.; Tafuri, A.; Cioffi, N.; Gallazzi, M.C.; Sassella, A.; Sabbatini, L.; Zambonin, P.G. Regioregular polythiophene field-effect transistors employed as chemical sensors. Sens. Actuator B Chem. 2003, 93, 257-262. [CrossRef]

33. Lv, A.; Wang, M.; Wang, Y.; Bo, Z.; Chi, L. Investigation into the sensing process of high-performance $\mathrm{H}_{2} \mathrm{~S}$ sensors based on polymer transistors. Chem. Eur. J. 2016, 22, 3654-3659. [CrossRef] [PubMed] 
34. Das, A.; Dost, R.; Richardson, T.H.; Grell, M.; Wedge, D.C.; Kell, D.B.; Morrison, J.J.; Turner, M.L. Low cost, portable, fast multiparameter data acquisition system for organic transistor odour sensors. Sens. Actuator B Chem. 2009, 137, 586-591. [CrossRef]

35. Dudhe, R.S.; Sinha, J.; Kumar, A.; Rao, V.R. Polymer composite-based OFET sensor with improved sensitivity towards nitro based explosive vapors. Sens. Actuator B Chem. 2010, 148, 158-165. [CrossRef]

36. Wang, F.; Gu, H.; Swager, T.M. Carbon nanotube/polythiophene chemiresistive sensors for chemical warfare agents. J. Am. Chem. Soc. 2008, 130, 5392-5393. [CrossRef] [PubMed]

37. Ohmori, Y.; Muro, K.; Yoshino, K. Gas-sensitive and temperature-dependent schottky-gated field-effect transistors utilizing poly(3-alkylthiophene)s. Synth. Met. 1993, 57, 4111-4116. [CrossRef]

38. Wang, B.; Huynh, T.P.; Wu, W.W.; Hayek, N.; Do, T.T.; Cancilla, J.C.; Torrecilla, J.S.; Nahid, M.M.; Colwell, J.M.; Gazit, O.M.; et al. A highly sensitive diketopyrrolopyrrole-based ambipolar transistor for selective detection and discrimination of xylene isomers. Adv. Mater. 2016, 28, 4012-4018. [CrossRef] [PubMed]

39. Chang, J.B.; Liu, V.; Subramanian, V.; Sivula, K.; Luscombe, C.; Murphy, A.; Liu, J.S.; Frechet, J.M.J. Printable polythiophene gas sensor array for low-cost electronic noses. J. Appl. Phys. 2006, 100, 014506. [CrossRef]

40. Wang, C.; Dong, H.; Hu, W.; Liu, Y.; Zhu, D. Semiconducting $\pi$-conjugated systems in field-effect transistors: A material odyssey of organic electronics. Chem. Rev. 2012, 112, 2208-2267. [CrossRef] [PubMed]

41. Janata, J. Conductometric sensors. In Principles of Chemical Sensors, 2nd ed.; Springer: Boston, MA, USA, 2009; pp. 241-266.

42. Janata, J.; Josowicz, M. Conducting polymers in electronic chemical sensors. Nat. Mater. 2003, 2, 19-24. [CrossRef] [PubMed]

43. Virji, S.; Huang, J.X.; Kaner, R.B.; Weiller, B.H. Polyaniline nanofiber gas sensors: Examination of response mechanisms. Nano Lett. 2004, 4, 491-496. [CrossRef]

44. Eom, K.H.; Hyun, K.H.; Lin, S.; Kim, J.W. The meat freshness monitoring system using the smart RFID tag. Int. J. Distrib. Sens. Netw. 2014, 2014, 591812. [CrossRef]

45. Naila, A.; Flint, S.; Fletcher, G.; Bremer, P.; Meerdink, G. Control of biogenic amines in food-existing and emerging approaches. J. Food Sci. 2010, 75, R139-R150. [CrossRef] [PubMed]

46. Liao, F.; Toney, M.F.; Subramanian, V. Thickness changes in polythiophene gas sensors exposed to vapor. Sens. Actuator B Chem. 2010, 148, 74-80. [CrossRef]

47. Ram, M.K.; Yavuz, O.; Aldissi, $\mathrm{M} . \mathrm{NO}_{2}$ gas sensing based on ordered ultrathin films of conducting polymer and its nanocomposite. Synth. Met. 2005, 151, 77-84. [CrossRef]

48. Chandrashekar, T.K.; Krishnan, V. Donor properties of metallomacrocyclic tetrapyrrole pigments with sym-trinitrobenzene. Inorg. Chem. 1981, 20, 2782-2786. [CrossRef]

49. Huynh, T.P.; Sharma, P.S.; Sosnowska, M.; D'Souza, F.; Kutner, W. Functionalized polythiophenes: Recognition materials for chemosensors and biosensors of superior sensitivity, selectivity, and detectability. Prog. Polym. Sci. 2015, 47, 1-25. [CrossRef]

50. Feng, L.R.; Tang, W.; Zhao, J.Q.; Yang, R.Z.; Hu, W.; Li, Q.F.; Wang, R.L.; Guo, X.J. Unencapsulated air-stable organic field effect transistor by all solution processes for low power vapor sensing. Sci. Rep. 2016, 6, 20671. [CrossRef] [PubMed]

51. Tanese, M.C.; Fine, D.; Dodabalapur, A.; Torsi, L. Organic thin-film transistor sensors: Interface dependent and gate bias enhanced responses. Microelectr. J. 2006, 37, 837-840. [CrossRef]

52. Tanese, M.C.; Fine, D.; Dodabalapur, A.; Torsi, L. Interface and gate bias dependence responses of sensing organic thin-film transistors. Biosens. Bioelectron. 2005, 21, 782-788. [CrossRef] [PubMed]

53. Covington, J.A.; Gardner, J.W.; Bartlett, P.N.; Toh, C.S. Conductive polymer gate fet devices for vapour sensing. IEE Proc.-Circuit Device Syst. 2004, 151, 326-334. [CrossRef]

54. Potje-Kamloth, K. Chemical gas sensors based on organic semiconductor polypyrrole. Crit. Rev. Anal. Chem. 2002, 32, 121-140. [CrossRef]

55. Meijerink, M.G.H.; Koudelka-Hep, M.; de Rooij, N.F.; Strike, D.J.; Hendrikse, J.; Olthuis, W.; Bergveld, P. Gas-dependent field effect transistor with an electrodeposited conducting polymer gate contact. Electrochem. Solid State Lett. 1999, 2, 138-139. [CrossRef]

(C) 2017 by the authors; licensee MDPI, Basel, Switzerland. This article is an open access article distributed under the terms and conditions of the Creative Commons Attribution (CC BY) license (http:/ / creativecommons.org/licenses/by/4.0/). 